\section{Ivan Mirnik}

samostalni istraživač

independent researcher

Mihanovićeva 32

Zagreb, Hrvatska

i.a.d.mirnik@gmail.com

iD orcid.org/0000-0002-7275-9142

Prethodno priopćenje

Preliminary communication

UDK / UDC:

737.2.041

75 Klović, J.

DOI:

10.17685/Peristil.63.3

Primljeno / Received:

20. 10. 2020.

Prihvaćeno / Accepted:

23. 11. 2020

\section{Julije Klović na medaljama i medaljonu}

\author{
Giulio Clovio on Medals and on a Medallion
}

\begin{abstract}
APSTRAKT
Za svog života Juraj Julije Klović portretiran je na medaljama dvaput - ukoliko nije riječ o dvije inačice iste medalje - a samo jedna medalja sačuvana je do danas i to u Odjelu za numizmatiku i medalje Britanskog muzeja u Londonu. Godine 1632. postavljen je u rimskoj crkvi nadgrobni spomenik J. J. Kloviću s mramornim ovalnim medaljonom s portretom velikoga majstora minijature. U drugoj polovini 17. stoljeća neki ne prevješti medaljer napravio je medalju s poprsjem osobe koja profilom ni u kom slučaju ne sliči Kloviću, iako natpis govori suprotno. Tijekom druge polovine 20. stoljeća neki hrvatski medaljeri (I. Belobrajdić, Z. Brkić, A. Kukec, K. Kovačić, D. Mataušić) posvećivali su Kloviću svoje radove, bilo s njegovim portretom, bilo s reminiscencijama na neke od njegovih vrlo brojnih radova.
\end{abstract}

\section{KLJUČNE RUEČI}

Julije Juraj Klović, medalje, numizmatika, portret

\begin{abstract}
During G. G. Clovio lifetime only two medals were made or perhaps just one in two variants with his portrait. Only one exists today, and it is kept at the Coins and Medals Department of the British Museum in London. In 1632 a representative marble epitaph consisting of an inscription topped by the miniaturist's portrait on an oval medallion was unveiled in Rome. In the second half of the 17th century, an untrained medallist made a medal with the bust of a person whose profile in no way resembles Clovio, although the inscription says the opposite. During the second half of the 2oth century, some Croatian medallists (I. Belobrajdić, Z. Brkić, A. Kukec, K. Kovačić, D. Mataušić) dedicated their works to Clovio, either with his portrait or with reminiscences of some of his very numerous works.
\end{abstract}

\section{KEYWORDS}

Giulio Giorgio Clovio, medals, numismatics, portrait 


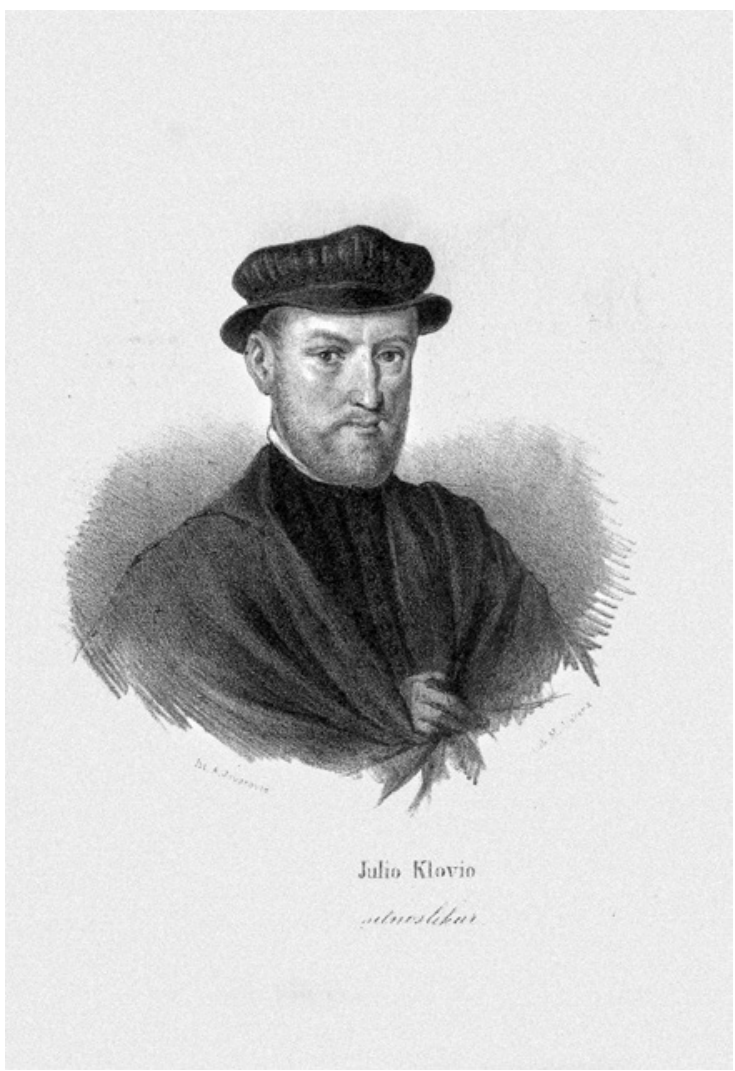

A. Jovanović - M. Beker, J. J. Klović, litografija (preuzeto iz: Kukuljević, 1858.)

A. Jovanović - M. Beker, G. G. Clovio, lithograph (source: Kukuljević, 1858)
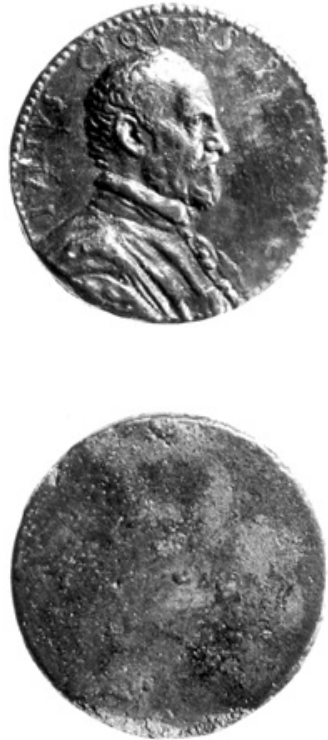
Nepoznati majstor, J. J. Klović, The British Museum

Anonymous medallist, G. G. Clovio, The British Museum
Potaknuti neobičnom činjenicom da su se nedavno u Zagrebu, u dvije različite privatne numizmatičke zbirke, pojavila dva primjerka iste lijevane apokrifne medalje iz 17. stoljeća s portretom za koji u natpisu kaže da bi to trebao biti Julije Klović, odlučili smo se pozabaviti Julijem Klovićem prikazanim na medaljama i na jednome medaljonu. Julije Juraj Klović (Grižane, 1498. - Rim, 5. siječnja 1578.) (sl. 1) ${ }^{1}$ - „maximus in minimis” - portretiran je na slikama, bakrorezima, posthumno i na poprsjima (od kojih se dva nalaze u Zagrebu, jedno, Rendićevo, na Zrinskom trgu, a drugo na Umjetničkom paviljonu) te na jednom medaljonu i više medalja. Premda se ne moramo žaliti da ga suvremeni veliki slikari nisu potretirali, ipak je neobično da su za njegova života nastale samo dvije portretne medalje, od kojih je sačuvana samo jedna; sve ostale nastale su kasnije, neke i u naše doba.
Jednu medalju, promjera $40 \mathrm{~mm}$, ali dvostranu, koja se nekad čuvala u Breri u Milanu, objelodanio je 1750. godine talijanski povjesničar i numizatičar Filippo Argelati (Bologna, prosinac 1685. - Milano, 25. siječnja 1755.):

„XIII. ClOVIVS (IVlivs) PICT. EXCEL. P. A. Mulier sedens inter arbores; illam ante stat Fortuna tubam inflans \&c. FAMA VIRTVTIS TVBICINA. Inf." ${ }_{2}$

I. Kukuljević - prema Tiraboschiju - navodi i to da se jedan otisak te medalje nalazio kod nekog oca Trombellija u samostanu sv. Spasitelja u Bologni. ${ }^{3} \mathrm{Tu}$ istu medalju, naravno ne de visu, opisuje i A. Armand u svom katalogu renesansnih medalja 15. i 16. stoljeća:

„Croatie. Clovio (Giulio), Croate, célèbre miniaturiste, né en $1498+1578$. H. Dia. 40 . „IVLIVS . CLOVIVS . PICT . EXCEL.” RV „FAMA . 


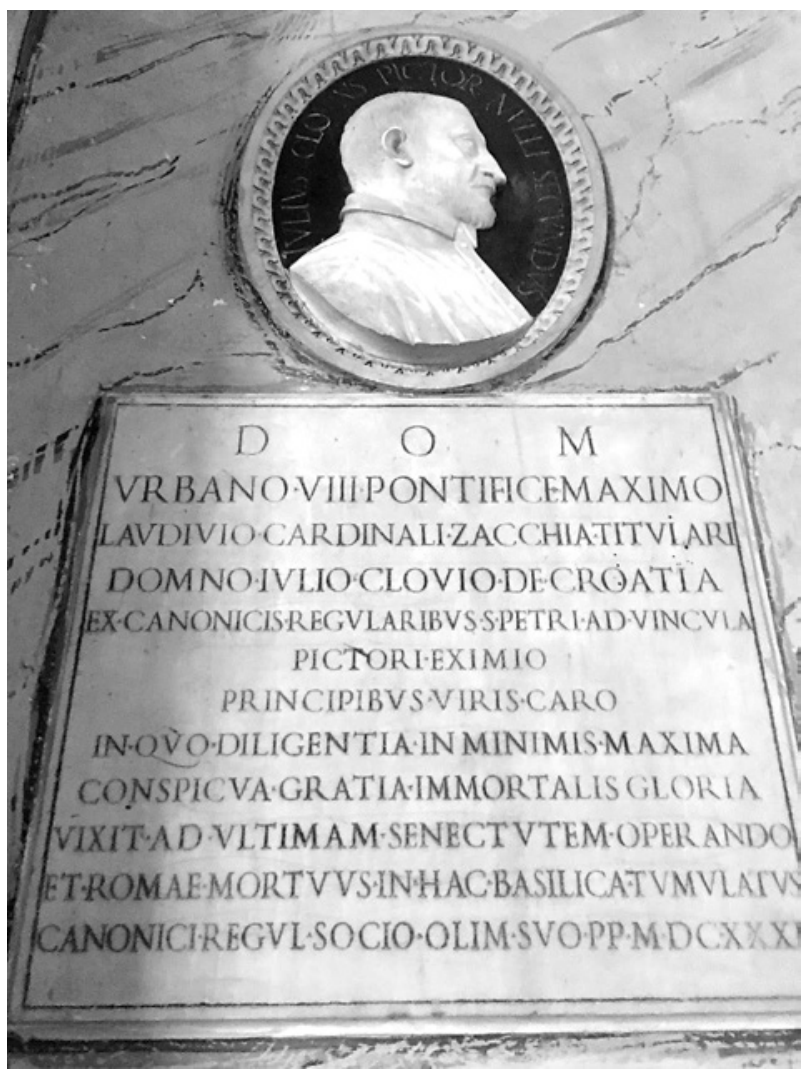

3 Epitaf J. J. Klovića, S. Pietro in Vincoli, Rim (foto: Jadranka Beresford-Peirse)

The epitaph of G. G. Clovio, S. Pietro in Vincoli, Rome (photo: Jadranka Beresford-Peirse)

VIRTUTIS . TVBICINA.” Au droit: Buste de Clovio, tête nue, barbu, habit civil. - Au revers: Une femme assise entre des arbres: devant elle, la Renommée, debout, sonnant de la trompette. - Soc. Colomb - Arg., III, p. $36 .^{4}$

Budući da se ne zna gdje se danas ta medalja čuva, i postoji li još uopće negdje, njezin se opis samo prenosi iz generacije u generaciju numizmatičara i drugih stručnjaka. ${ }^{5}$

Jednostranu medalju, nastalu približno 1560. godine, također od lijevane bronce (sl. 2), sačuvanu u Britanskome muzeju u Londonu, objavio je najprije John W. Bradley 1891. nasuprot naslovne stranice, ${ }^{6}$ a u novije vrijeme objelodanili su je i M. Pelc ${ }^{7}$ te P. Attwood: ${ }^{8}$

IVLIVS CLOVIVS PICT. EXc. Poprsje Julija Klovića, s bradom, u haljetku, s okovratnikom, nadesno. Biserni okvir. Lijevana bronca. Ø $32 \mathrm{~mm}$.

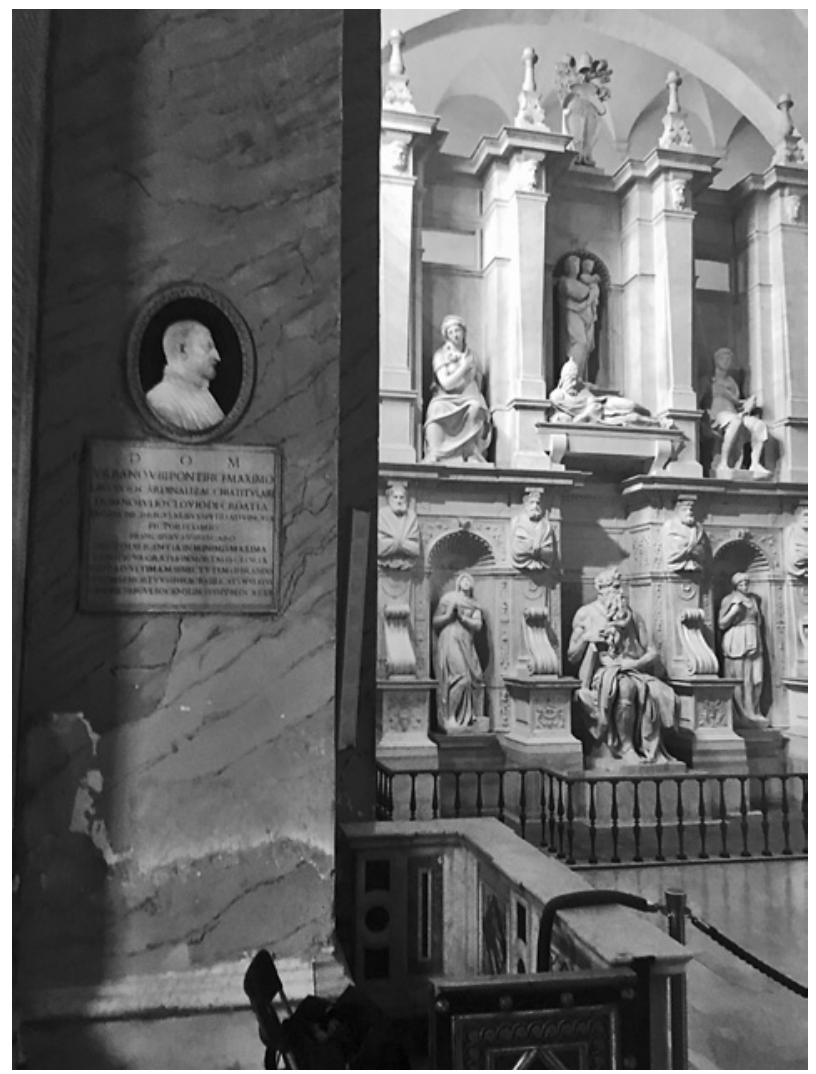

4 Epitaf J. J. Klovića s Michelangelovim spomenikom papi Juliju II. u pozadini, S. Pietro in Vincoli, Rim (foto: J. Beresford-Peirse)

The epitaph of G. G. Clovio with the monument of Pope Julius II by Michelangelo, S. Pietro in Vincoli, Rome (photo: J. Beresford-Peirse)
Možda je to inačica prethodno opisane dvostrane medalje za koju je vrlo poznat, te još i danas citirani britanski numizmatičar, Herbert Appold Grueber (Hambridge, Somerset, 1846. - Bembridge, the Isle of Wight, 21. studenoga 1927.), pretpostavljao da je rad poznatog medaljera Piera Paola Galeottija, zvanog Romano, iako je ne nalazimo u popisima radova tog medaljera, ${ }^{9}$ a ni P. Attwood nije ponovio tu atribuciju. Natpis na licu medalje gotovo je isti kao i kod dvostrane medalje, tek umjesto EXCEL čitamo EXC.

H. A. Grueber pisao je, dakle, J. W. Bradleyu sljedeće: „Na Klovićevoj medalji nema ničega što bi nam pokazalo zašto i kada je napravljena. Veći broj talijanskih medalja su spomen-medalje i najčešće se općenito odnose na karakter portretirane osobe. Klovićeva medalja načinjena je relativno kasno u njegovu životu, približno 1560., a sudeći 


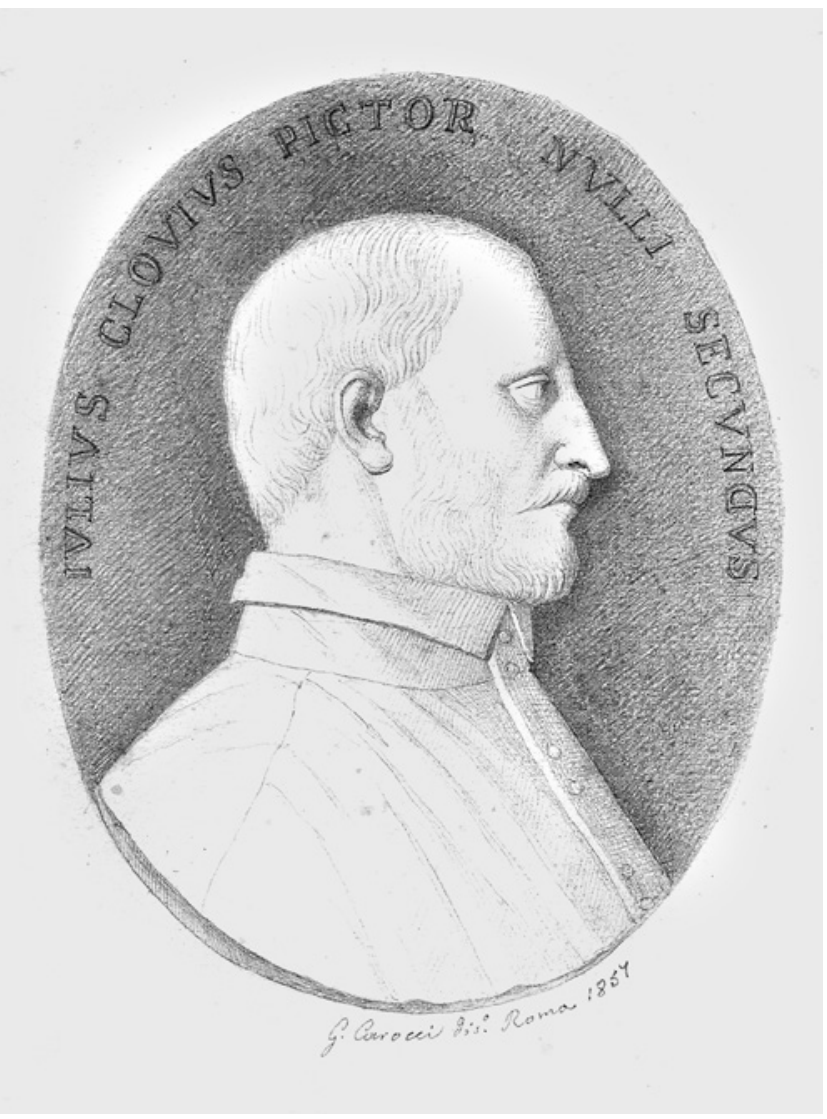

5 Medaljon s portretom J. J. Klovića, S. Pietro in Vincoli, Rim, crtež u olovci prema grafici G. Garoccija (Rim, 1837.), arhiv Arheološkog muzeja u Zagrebu

Medallion with the portrait of G. G. Clovio, S. Pietro in Vincoli, Rome, drawing in pencil after an engraving by G. Garocci (Rome, 1837), Archives of the Zagreb Archaeological Museum
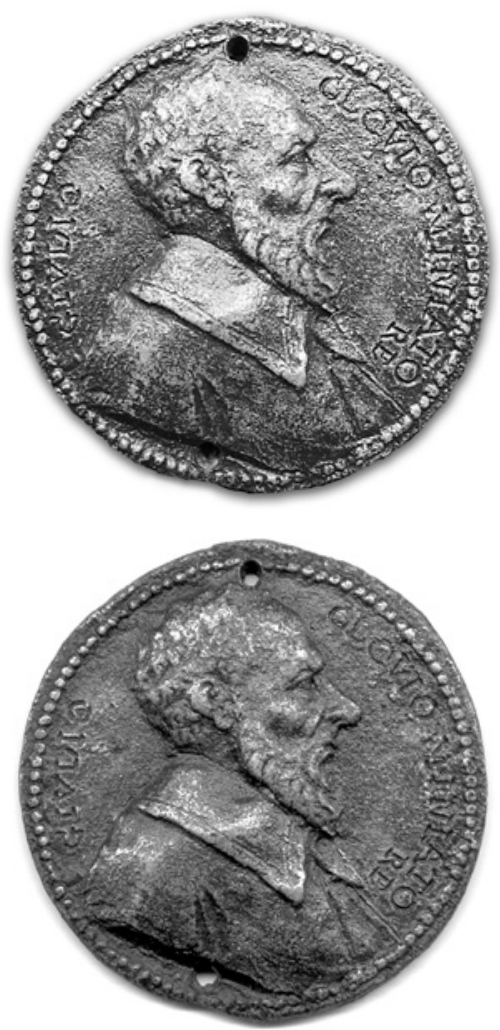

6a Portretna medalja J. J. Klovića, druga polovina 17. st., lijevana bronca, Ø 48,5 mm, 47,95 g, privatna zbirka, Zagreb

Portrait medal of G. G. Clovio, second half of 17th c., cast bronze, $\emptyset 48.5 \mathrm{~mm}, 47.95 \mathrm{~g}$, private collection, Zagreb

6b Portretna medalja J. J. Klovića, druga polovina 17. st., lijevana bronca, $\varnothing 48 \mathrm{~mm}, 42,78 \mathrm{~g}$, privatna zbirka, Zagreb

Portrait medal of G. G. Clovio, second half of 17th c., cast bronze, $\emptyset 48 \mathrm{~mm}, 42.78 \mathrm{~g}$, private collection, Zagreb

napis završava s EXCEL, a na naličju je ženski lik koji sjedi izmedu stabala: pred njom Fama puše u trublju, natpis je: FAMA VIRTVTIS TVBICINA.

U jednom kasnijem pismu, Grueber predlaže da bi Braydensis teško mogao biti Breda u Holandiji, kako bi se to činilo, no, naravno nije mogao reći što to znači, jer nije vidio medalju. Nisam je ni ja vidio, a čini mi se da nije ni Argelati, ili da se zabunio. Budući da sam negdje vidio bilješku da jedna Klovićeva medalja postoji u muzeju Brera u Milanu, trebao bih pomisliti da je to mjesto na koje se mislilo. Žao mi je da, kad sam boravio u Milanu nisam tu opasku vidio prije, tako da ne mogu potvrditi da li je to pravo objašnjenje." ${ }^{10}$ 

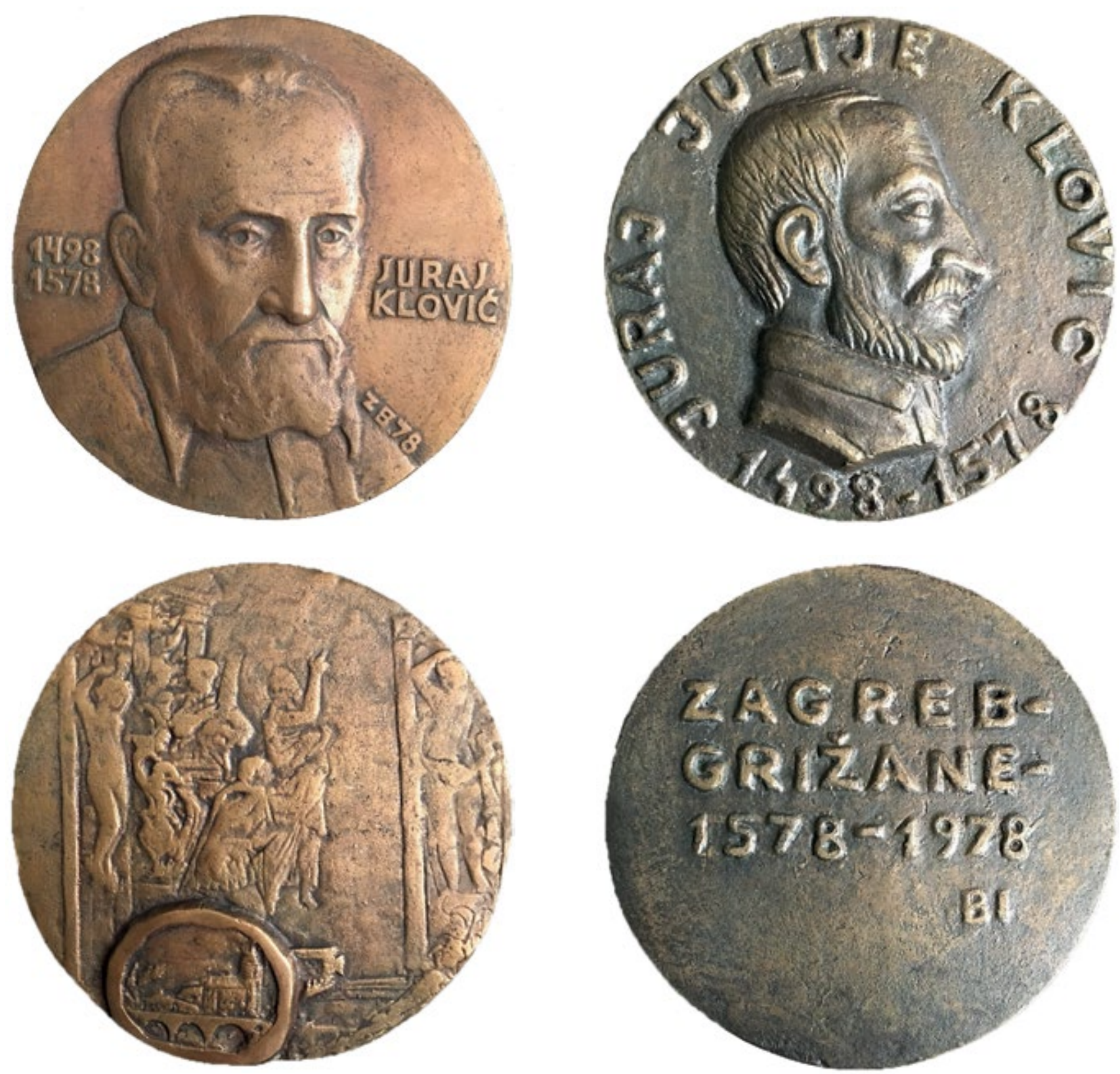

7 Zdravko Brkić, J. J. Klović, 1978., dvostrana lijevana brončana medalja, Ø $115 \mathrm{~mm}$, privatna zbirka, Zagreb

Zdravko Brkić, G. G. Clovio, 1978, two-sided cast-bronze medal, Ø $115 \mathrm{~mm}$, private collection, Zagreb

8 Ivan Belobrajdić, J. J. Klović, 1978., dvostrana lijevana brončana medalja, Ø $78 \mathrm{~mm}$, privatna zbirka, Zagreb

Ivan Belobrajdić, G. G. Clovio, 1978, two-sided cast-bronze medal, $\varnothing 78 \mathrm{~mm}$, private collection, Zagreb 


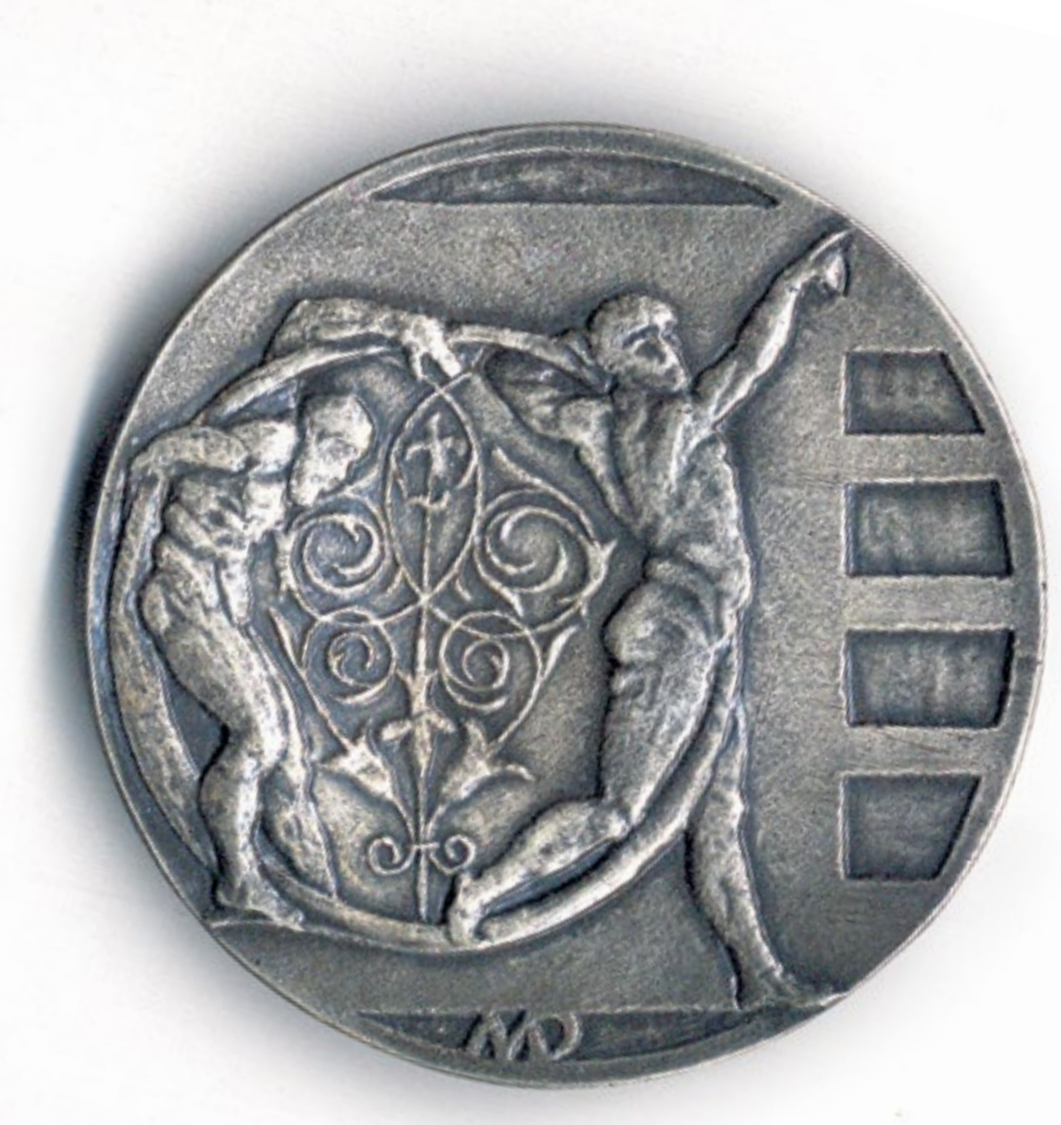

9 Damir Mataušić, dekanski lanac Akademije likovnih umjetnosti u Zagrebu - inicijal „O” prema J. J. Kloviću, 1979., nereducirana medalja, posrebrena bronca, $99 \mathrm{~mm}$, Arheološki muzej u Zagrebu, Numizmatički odjel, inv. br. E48713

Damir Mataušić, the chain of the Dean of the Academy of Fine Arts in Zagreb - the initial "O" after G G. Clovio, 1979, unreduced medal, silver-plated bronze, $99 \mathrm{~mm}$, The Zagreb Archaeological Museum Numismatic Department, inv. No. E48713

Udaljenost izmedu pojma medalje (u malom formatu $)^{11} \mathrm{i}-\mathrm{u}$ numizmatičkomu smislu - medaljona (u velikom formatu) ${ }^{12}$ nije velika, budući da je riječ o istom reljefnom načinu prikazivanja odredene teme, pa tako i portreta. Tako ćemo naići i na jedan veliki medaljon s portretom Jurja Julija Klovića. Naime, 1632., pedeset i četiri godine nakon Klovićeve smrti, u vrlo posjećivanoj glasovitoj rimskoj bazilici San Pietro in Vincoli, postavljen je njegov mramorni epitaf s opširnim natpisom (sl. 3), a iznad njega nalazi se ovalni medaljon s potretom minijaturista u profilu, okrenutom nadesno, i natpisom IVLIVS CLOVIVS PICTOR NVLLI SECVNDVS (sl. 3 i 4). Jedan crtež tog medaljona, u olovci, a prema grafici G. Garoccija (Rim, 1837.), čuva se u arhivu Arheološkoga muzeja u Zagrebu (sl. 5).

Godine 1998., u drugom svesku monumentalnog kataloga mletačkih medalja pisca i sakupljača
Piera Voltoline, mogli smo uočiti i jednu apokrifnu medalju s navodnim Klovićevim portretom (sl. 6), iz druge polovine 17. stoljeća, od lijevane bronce. ${ }^{13}$ Mogli smo je vidjeti i na izložbi „Medalje i plakete Istre i Kvarnera" u Muzeju grada Rijeke 2013. godine, ${ }^{14}$ a ta se medalja u još jednom primjerku, $\mathrm{u}$ vrijeme pisanja ovog članka, nalazila u Zagrebu. I u ovom slučaju, riječ je o lijevanoj, dvaput probušenoj medalji:

GIVLIO - CLOVIO MINIATO/RE (upuštena slova). Poprsje, kraće kose, bradato, u haljetku, sa širokim okovratnikom, nad. Biserni okvir. Lijevana bronca. Ø 48,5 mm.

U ovom slučaju, portret Klovića nikako ne odgovara nijednome od njegovih portreta iz onog vemena, pa tako ni onome na prethodno opisanoj medalji iz Britanskog muzeja, a ni na medaljonu uzidanom iznad Klovićeva epitafa, već više 


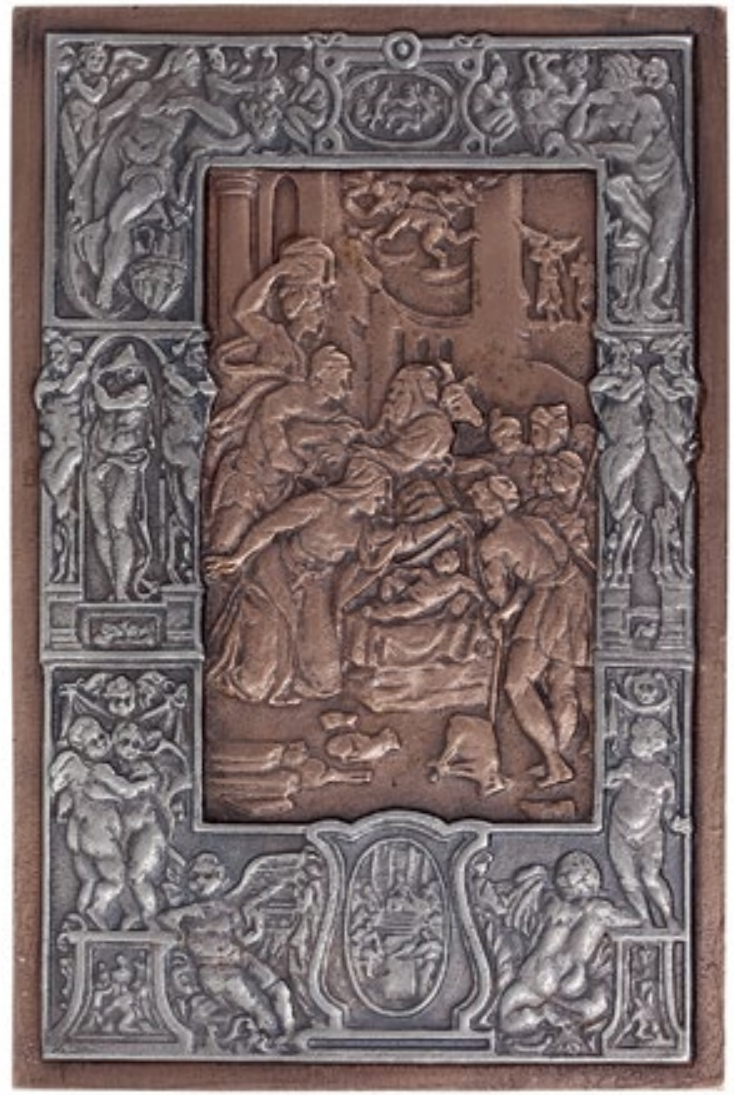

10a Damir Mataušić, Poklonstvo pastira prema J. J. Kloviću, plaketa, bronca djelomično posrebrena, $250 \times 165 \mathrm{~mm}$

Damir Mataušić, Adoration of the Shepherds, after G. G. Clovio, bronze, partly silver-plated, $165 \times 250 \mathrm{~mm}$

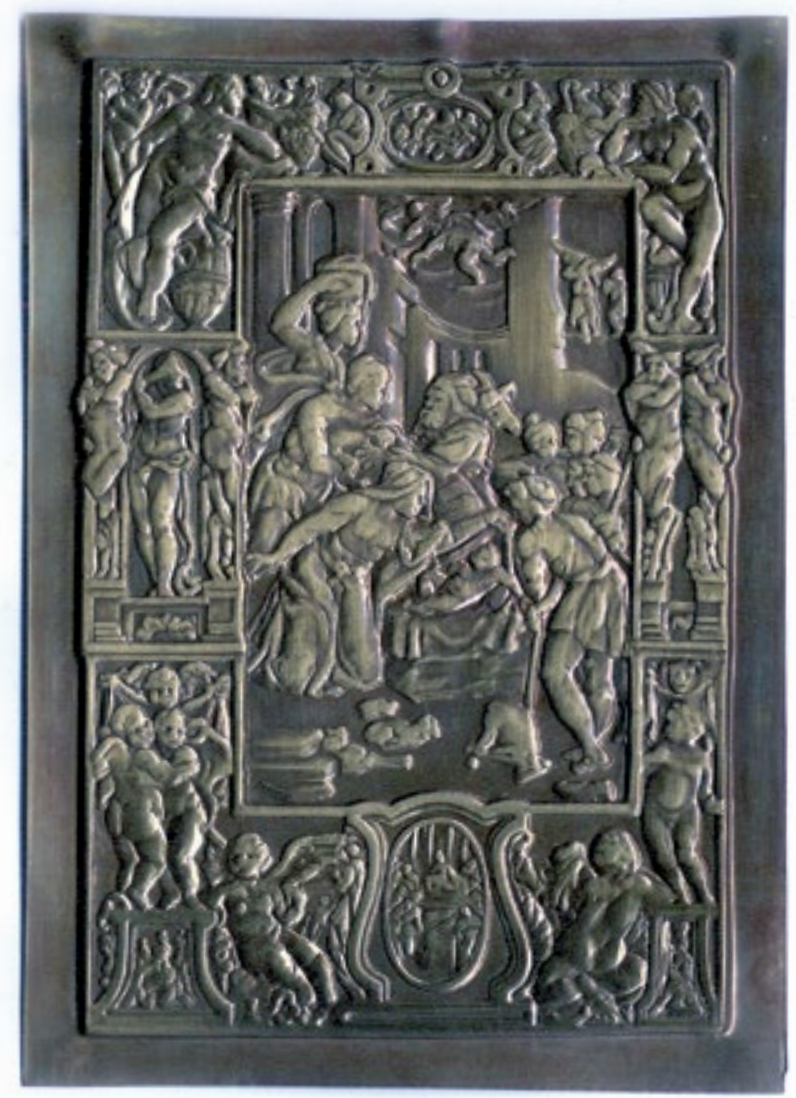

10b Damir Mataušić, Poklonstvo pastira prema J. J. Kloviću, plaketa, tiješteni bakar, $72 \times 110 \mathrm{~mm}$, Arheološki muzej u Zagrebu, Numizmatički odjel, inv. br. E54462

Damir Mataušić, Adoration of the Shepherds after G G. Clovio, copper, $72 \times 110 \mathrm{~mm}$, The Zagreb Archaeological Museum, Numismatic Department, inv. No. E54462

Te iste godine, u kojoj se obilježavala četiristota godišnjica Klovićeve smrti, lijevana je još jedna, takoder dvostrana medalja (sl. 8), autora signiranog inicijalima B. I. - Ivan Belobrajdić. ${ }^{17}$

Lice: JURAJ JULIJE KLOVIĆ gore; 1498-1578 dolje. Poprsje J. Klovića nadesno. Naličje: ZAGREB-/GRIŽANE/1578-1978 (u tri retka). Signatura dolje desno: BI. Lijevana bronca. $\varnothing$ $78 \mathrm{~mm}$.

I Damir Mataušić (Zagreb, 15. lipnja 1954.), naš najplodniji medaljer današnjice, na jednoj je medalji i na jednoj plaketi majstorski pružio reminiscencije na neka Klovićeva djela: na jednoj od medalja na dekanskom lancu Akademije likovnih umjetnosti u Zagrebu (1979.) (sl. 9), ${ }^{18}$ kao i na plaketi s reinterpretacijom Klovićevog prikaza Poklonstva pastira, u izdanju nekadašnjega $\mathrm{Mu}-$ zejsko-galerijskog prostora na Jezuitskom trgu u 

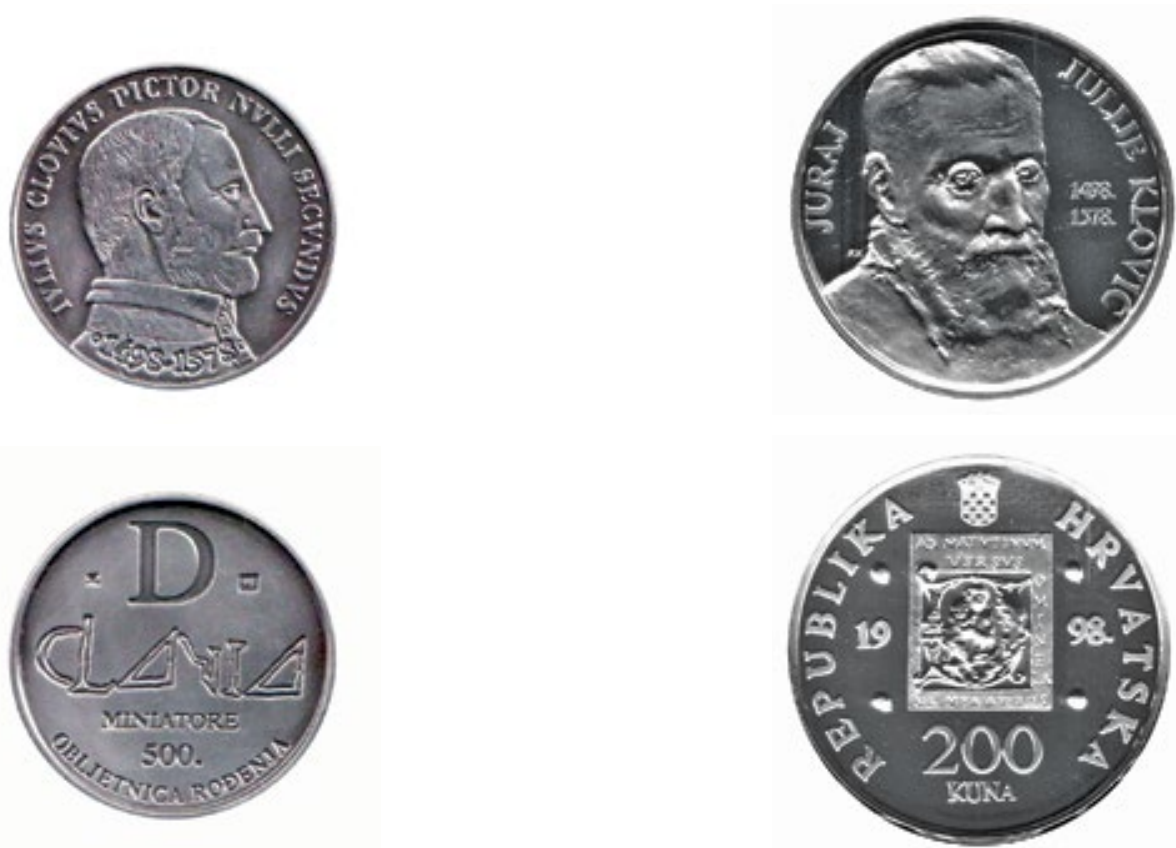

11 Aleksandar Kukec, J. J. Klović, 50o. obljetnica rođenja, 1998., srebro, $34 \mathrm{~mm}$, vlasništvo umjetnika

Aleksandar Kukec, G. G. Clovio, 500 years since his birth, 1998, silver, $34 \mathrm{~mm}$, the artist's collection

Zagrebu 1999. godine, u dvije inačice u različitim kovinama (bronca djelomično posrebrena bakreni lim, $72 \times 110 \mathrm{~mm}$ ) (sl. 10a i 10b). Veća plaketa, iskovana u srebru u Hrvatskom novčarskom zavodu u Zagrebu, poklonjena je papi Ivanu Pavlu II. 2003. godine.

Jedna medalja, nastala 1998. godine, a u povodu 500. obljetnice Klovićeva rođenja (sl. 11), djelo je Aleksandra Kukeca (Koprivnica, 8. srpnja 1931). ${ }^{19}$ Izrađena je neuobičajenom tehnologijom, osnovanoj na umjetnosti fotografije.

Lice: IVLIVS CLOVIVS PICTOR NVLLI SECVNDVS; .1498-1578. dolje. Poprsje J. Klovića, u haljetku s ovratnikom, nadesno. Linearni okvir. Naličje: D/ CLOVIO/ MINIATORE/ 500./ OBLJETNICA ROĐENJA (tri različita tipa slova), u pet redaka. Dvije punce gore lijevo i desno. Linearni okvir. Srebro. Ø $38 \mathrm{~mm} .^{20}$
12 Kuzma Kovačić, Republika Hrvatska, J. J. Klović, 500. obljetnica rođenja, 1998., 200 kuna, srebro, $40 \mathrm{~mm}$, Arheološki muzej u Zagrebu, Numizmatički odjel, inv. br. E48366

Kuzma Kovačić, Republic of Croatia, G. G. Clovio, 500 years since his birth, 1998, silver, 200 kuna, 40 mm, The Zagreb Archaeological Museum, Numismatic Department, inv. No. E48366

Posebno je važan apoen u vrijednosti od 200 kuna u srebru, nastao isto tako u povodu 500. obljetnice rođenja Jurja Julija Klovića (iskovan u Hrvatskom novčarskom zavodu u Zagrebu), autora Kuzme Kovačića (Hvar, 6. lipnja 1952.). Izradi je prethodio uobičajeni natječaj Hrvatske narodne banke, na koji su umjetnici poslali svoje crteže. Nakon užeg izbora troje umjetnika (Zdravko Brkić, Maja Krstić-Lukač i Kuzma Kovačić), zamoljeni su da izrade sadreni model, a odabran je onaj Kuzme Kovačića (sl. 12 i 13):

Lice: JURAJ - JULIJE KLOVIĆ; poprsje J. Klovića u poluprofilu nadesno (prema portretu El Greca, nastalom po Klovićevom autoportretu u Firenci) 1487/1578 desno u polju; signatura. dolje lijevo u polju KK. Linearni okvir. Naličje: REPUBLIKa (grb Republike Hrvatske) HRVATSKA; detalj minijature iz Londonskog 

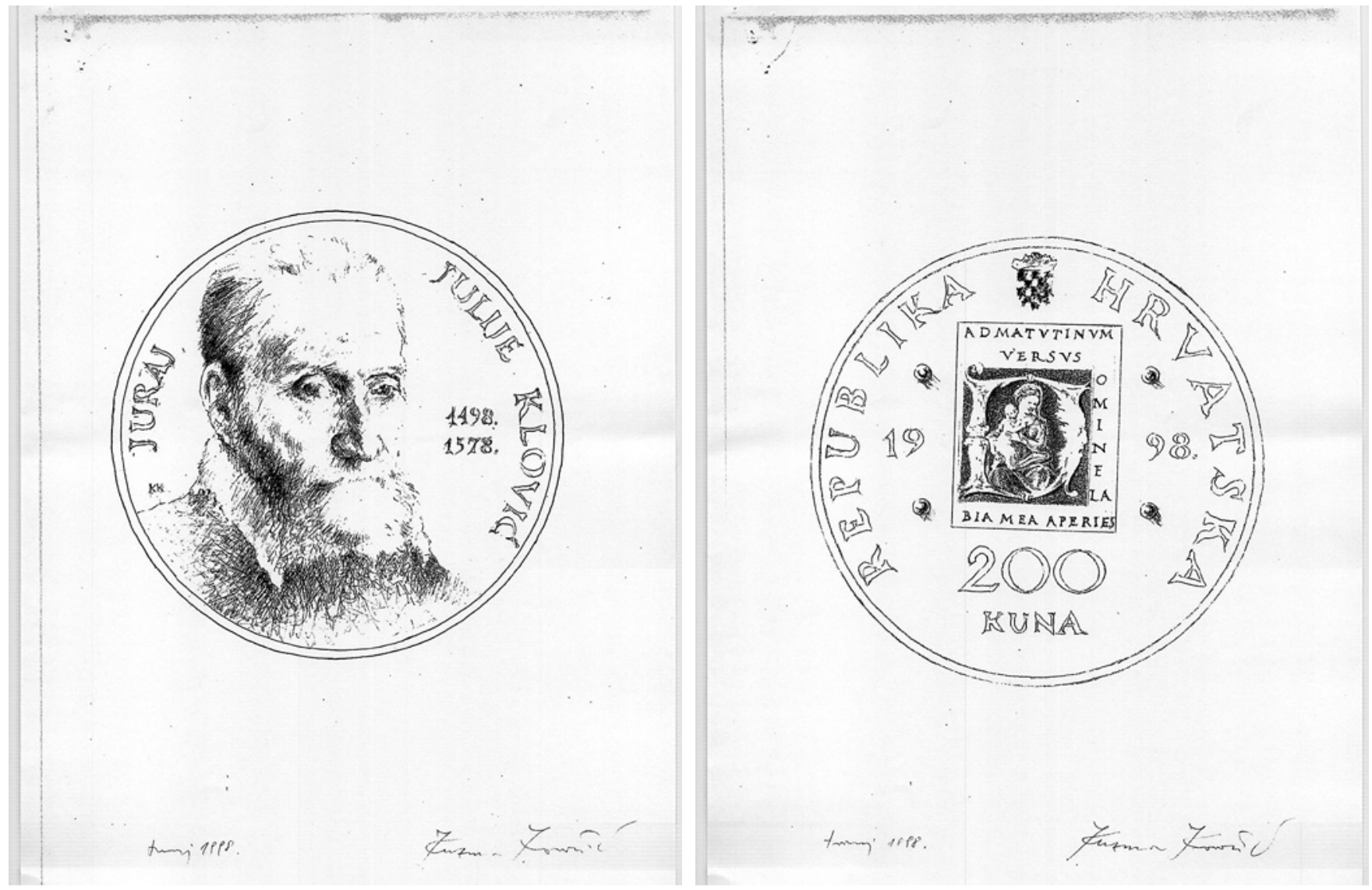

13 Kuzma Kovačić, crtež za kovanicu od 200 kuna u povodu 500. obljetnice rođenja J. J. Klovića, 1998., Ø 145 mm, Hrvatska narodna banka, Zagreb

Kuzma Kovačić, drawing for the 200 kuna coin dedicated to the 500 years since the birth of G. G. Clovio, 1998, Ø $145 \mathrm{~mm}$, The Croatian National Bank, Zagreb

časoslova: između četiri točke inicijal iz kodeksa „Beatissime Mariae Virginis Officium” (fol. 14 R, časoslova Stuart de Rothesay u Britanskome muzeju) D, koji sadrži Bogorodicu s Isusom (uklopljen u natpis: AD MATVTINVM VERSUS DOMINE LABIA MEA APERIES); 19 - 98. lijevo i desno u polju; 200/KUNA dolje. Linearni okvir. AR, T.: 33,63 g. Dim.: Ø 40mm. Kartonski etui. 538:ZAG E48366. (Hrvatska narodna banka, dar 1998. $)^{21}$

Sadreni modeli K. Kovačića za obje strane te nominale od 200 kuna $^{22}$ čuvaju se u Numizmatičkoj zbirci Arheološkog muzeja u Zagrebu (Ø 150 $\mathrm{mm}$; E64105-6).

Očekujmo i u budućnosti da će se naši kipari, slikari i medaljeri povremeno sjetiti Klovića i inspirirati se njegovim prelijepim i ogromnim opusom.
Najsrdačnije zahvaljujem brojnim prijateljima i kolegama koji su mi u ovo kratko vrijeme pisanja članka o J. Kloviću na medaljama priskočili u pomoć: Philip Attwood, Lady Jadranka Beresford-Peirse, Damir Bićanić, Andrew Burnett, Robert Kavazović, Aleksandar Kukec, Miroslav Nad, Rodolfo Martini, Damir Mataušić, Milan Pelc, Petra Poldrugač, Marko Šarinić, Novella Vismara. 


\section{BILJEŠKE}

1 Ivan Kukuljević-Sakcinski, Leben des G. Julius Clovio, ein Beitrag zur slawischen Kustgeschichte (Agram: Franz Suppan's Buchdruckerei, 1852.); Ivan Kukuljević-Sakcinski, Slovnik umjetnikah jugoslavenskih (Zagreb: Tiskom Narodne tiskarne dra. Ljudevita Gaja, 1858.), 155-188; Ivan Kukuljević-Sakcinski, Jure Glović prozvan Julio Klovio: hrvatski slitnoslikar (Zagreb: Naklada Matice hrvatske, 1878. - reprint: Družba Braća Hrvatskoga Zmaja, 200o.); Giorgio Vasari, Le vite de più eccelenti pittori scultori ed architetti scritte da Giorgio Vasari pittore aretino con nuove annotazioni e commenti dai Gaetano Milanesi, Vol. VII (Milano: G.C. Sansoni, 1881.), 557-589.

2 Philippus Argelatus, ,Tabulae monetarum veterum ex museo Braydensis universitatis Societatis Jesu," in De monetis Italiae variorum illustrium virorum dissertationes quarum pars nunc primum in lucem prodit Philippus Argelatus Bononiensis Collegit, recensuit, necnon Indicibus locupletissimis exornavit, vol. III (Mediolani: "Prostant in Regia curia in Aedibus Palatinis", 1750.) 36; Kukuljević-Sakcinski, Slovnik, 178.

3 Girolamo Tiraboschi, Storia della letteratura italiana, Vol. VII, 3 (Modena: Società tipografica, 1779.), 407-408.

4 Alfred Armand, Les médailleurs italiens des quinzième et seizième siècles, vol. III (Paris: E. Plon et Compagnie, 1887.) 279.

5 Milan Pelc, Fontes Clovianae: Julije Klović u dokumentima svoga doba (Zagreb: Matica hrvatska, 1998.), 172, 273-274.

6 John W. Bradley, The Life and Works of Giorgio Giulio Clovio, with Notices of His Contemporaries, and of the Art of Book Decoration in the Sixteenth Century (London: Bernard Quaritch, 1891.), 370-371.

7 Pelc, Fontes Clovianae, 172, 273-274.

8 Philip Attwood, Italian medals c.1530-160o in British public collections (London: British Museum Press, 2003.) 424, br. 1048.

9 Leonard Forrer, Biographical Dictionary of Medallists Coin-, Gem-. and Seal-Engravers Mint-Masters, \&c. Ancient and Modern with References to Their Works B.C. 500 - A.D. 1900 Compiled by..., vol. II (London: Spink \& Son Ltd., 1904.), 190-194.

10 „There is nothing in the Clovio medal to show why or when it was made. The larger number of Italian medals are merely commemorative, referring in a general manner to the character of the person portrayed. The medal of Clovio was made rather late in his life, circ. 1560, and judging from its style of work, I would give it to the hand of Pietro Paolo Galeotti, called Romano. The Museum specimen is a poor cast; but I think its original must have been of very good work. The portrait, I should say, is quite authentic, and the piece is unknown, i. e. unpublished, so if you illustrate it, it will be for the first time.

P.S. I ought to have said that the original was a cast medal made from moulds, not struck from dies. This is quite characteristic for Romano's work. Argelati „De Monetis Italiae Milan 1750, iii, 36" describes one as being in the "Braydensis" collection. The obverse is the same as the B.M. cast IVLIVS CLOVIVS PICT.EXC, but the inscription ends EXCEL. and on the reverse is a female seated between trees: before her Fame blowing a trumpet, leg. FAMA VIRTVTIS TVBICINA."

In a later communication, Mr. Grueber suggests that the „Braydensis can hardly mean Breda in Holland, as it would seem to, but of course he could not say what it means, as he had not seen the medal itself. Neither have I, but it seems to me that Argelati had not either, or that he made some mistake. As I have seen somewhere a note that a medal of Clovio exists in the Brera Museum in Milan, I should think this to be the locality meant. I regret that when in Milan I had not seen the note I refer to, so cannot affirm this to be the true explanation." Bradley, The Life and Works of Giorgio Giulio Clovio, 273-274.

11 Friedrich Schrötter, Wörterbuch der Münzkunde (Berlin-Leipzig: De Gruyter, 1930.), 379-382; Antun Bauer i drugi, Numizmatički priručnik i rječnik (Zagreb: Arheološki muzej u Zagrebu, 2011.), 335-341.

12 Schrötter, Wörterbuch der Münzkunde, 382-383.

13 Piero Voltolina, La storia di Venezia attraverso le medaglie, Vol. II (Venezia - Mestre: Edizioni Voltolina, 1998.), 342343 , br. 1148

14 Marko Šarinić, Medalje i plakete Istre i Kvarnera, katalog izložbe (Zagreb, 2013.), 13, br. 13.

15 Voltolina, La storia di Venezia, 120-121, br. 947-948.

16 Vinko Zlamalik, Memorijal Ive Kerdića (Osijek - Zagreb: Galerija likovnih umjetnosti Osijek - Strossmayerova galerija starih majstora Jugoslavenske akademije znanosti i umjetnosti Zagreb - Društvo povjesničara umjetnosti SR Hrvatske Zagreb, 1980.), 220-221, br. 698; Gjuro Krasnov i Vesna Mažuran-Subotić, Dvanaest hrvatskih medaljera (Zagreb: Muzejsko galerijski centar, 1988.), 24, br. 7; Šarinić, Medalje i plakete, 13, br. 14.

17 Ivan Golub, „Četiristota godišnjica smrti Jurja Julija Klovića, Croatae," Croatica Christiana periodica, 3 , 3 (1979): 197; Šarinić, Medalje i plakete, 14, br. 15.

18 Feđa Vukić, Damir Mataušić (Zagreb: GZH, 1993.), 78-79; Bogdan Mesinger, Medaljer Damir Mataušić, (Varaždin Zagreb: Galerija - Garestin Varaždin - Muzejsko galerijski centar Klovićevi dvori Zagreb, 1998.), 40-41; Ivan Mirnik, Numizmatička zbirka Arheološkoga muzeja u Zagrebu. Donacije 1990.-2010. The Numismatic Collection of the Zagreb Archaeological Museum. Donations 1990-2010 (Zagreb: Arheološki muzej u Zagrebu, 2010.), 135, br. 496; Tatijana Gareljić, Damir Mataušić, Kritička retrospektiva, 1974.-2020. / A Critical Retrospective, 1974.-2020. (Zagreb: Moderna galerija, 2020.), 12, 80.

19 Tonko Maroević, Svjetlopisi Aleksandra Kukeca (Zagreb: Školska knjiga, 2020.)

20 Andrija Mutnjaković, ur., Hommage Juliju Kloviću: izložba malih formata, u čast velikog minijaturiste, povodom 500. godišnjice rođenja, 1498-1998.: katalog, Acta et studia draconica, vol. III (Zagreb: Družba „Braća Hrvatskoga Zmaja”, 2000.), 10.

21 Mirnik, Numizmatička zbirka Arheološkoga muzeja 47, br. 87.

22 Mutnjaković, ur., Hommage Juliju Kloviću, 16-17. 


\section{REFERENCES}

Argelatus, Philippus. "Tabulae monetarum veterum ex museo Braydensis universitatis Societatis Jesu." In De monetis Italiae variorum illustrium virorum dissertationes quarum pars nunc primum in lucem prodit Philippus Argelatus Bononiensis Collegit, recensuit, necnon Indicibus locupletissimis exornavit, vol. III. Mediolani: "Prostant in Regia curia in Aedibus Palatinis", 1750.

Armand, Alfred. Les médailleurs italiens des quinzième et seizième siècles, vol. III. Paris: E. Plon et Compagnie, 1887.

Attwood, Philip. Italian medals C.1530-1600 in British public collections. London: British Museum Press, 2003.

Bauer, Antun, Kamilo Dočkal, Vladimir Liščić, Günther Probszt, Ivan Rengjeo, Vinko Zlamalik and Bartol Zmajić. Numizmatički priručnik i rječnik. Collectanea archaeologica Musei archaeologici Zagrabiensis. Sabrani radovi - Arheološki muzej u Zagrebu. Edited by Ivan Mirnik. Zagreb: Arheološki muzej u Zagrebu, 2011.

Bradley, John W. The Life and Works of Giorgio Giulio Clovio, with Notices of His Contemporaries, and of the Art of Book Decoration in the Sixteenth Century. London, 1891.

Forrer, Leonard. Biographical Dictionary of Medallists coin, gem-. and seal-engravers mint-masters, \&c. ancient and modern with references to their works B.C. 500 - A.D. 1900 compiled by..., vol. II. London: Spink \& Son Ltd., 1904.

Gareljić, Tatijana. Damir Mataušić, Kritička retrospektiva, 1974.-2020. / A Critical Retrospective, 1974.-2020. Zagreb: Moderna galerija, 2020. Exhibition catalog.

Golub, Ivan. "Četiristota godišnjica smrti Jurja Julija Klovića Croatae." Croatica Christiana periodica 3, no. 3 (1979): 197-198.

Krasnov, Gjuro, and Vesna Mažuran-Subotić. Dvanaest hrvatskih medaljera. Zagreb: Muzejsko-galerijski centar 1988. Exhibition catalog.

Kukuljević-Sakcinski, Ivan. Leben des G. Julius Clovio, ein Beitrag zur slawischen Kustgeschichte. Agram: Franz Suppan's Buchdruckerei, 1852.

Kukuljević-Sakcinski, Ivan. Slovnik umjetnikah jugoslavenskih. Zagreb: Tiskom Narodne tiskarne dra. Ljudevita Gaja, 1858.

Kukuljević-Sakcinski, Ivan. Jure Glović prozvan Julio Klovio: hrvatski slitnoslikar. Zagreb: Naklada Matice hrvatske, 1878. - reprint: Družba Braća Hrvatskoga Zmaja, 2000.

Maroević, Tonko. Svjetlopisi Aleksandra Kukeca. Zagreb: Školska knjiga, 2020.

Mesinger, Bogdan. Medaljer Damir Mataušić. Varaždin Zagreb: Galerija - Garestin Varaždin - Muzejsko galerijski centar Klovićevi dvori Zagreb, 1998.

Mirnik, Ivan. Numizmatička zbirka Arheološkoga muzeja u Zagrebu. Donacije 1990.-2010. The Numismatic Collection of the Zagreb Archaeological Museum. Donations 1990-2010, Zagreb: Arheološki muzej u Zagrebu, 2010.

Mutnjaković, Andrija, ed. Hommage Juliju Kloviću: izložba malih formata, u čast velikog minijaturiste, povodom 500. godišnjice rođenja, 1498-1998.: katalog, Acta et studia draconica, vol. III. Zagreb: Družba Braća Hrvatskoga Zmaja, 2000.

Šarinić, Marko. Medalje i plakete Istre i Kvarnera. Zagreb, 2013. Exhibition catalog.

Tiraboschi, Girolamo. Storia della letteratura italiana, vol. VII, 3. Modena: Società tipografica, 1779.

Pelc, Milan. Fontes Clovianae: Julije Klović u dokumentima svoga doba. Zagreb: Matica Hrvatska, 1998.

Schrötter, Friedrich. Wörterbuch der Münzkunde. Berlin Leipzig: Verlag von Walther de Gruyter \& Co, 1930.

Vasari, Giorgio. Le vite de più eccelenti pittori scultori ed architetti scritte da Giorgio Vasari pittore aretino con nuove annotazioni e commenti dai Gaetano Milanesi, Vol. VII. Milano G.C. Sansoni, 1881.
Voltolina, Giorgio. La storia di Venezia attraverso le medaglie, Vol. II. Venezia - Mestre: Edizioni Voltolina, 1998.

Vukić, Feđa. Damir Mataušić. Zagreb: GZH, 1993.

Zlamalik, Vinko. Memorijal Ive Kerdića. Osijek - Zagreb: Galerija likovnih umjetnosti Osijek - Strossmayerova galerija starih majstora Jugoslavenske akademije znanosti i umjetnosti Zagreb - Društvo povjesničara umjetnosti SR Hrvatske Zagreb, 1980. 


\section{SUMMARY}

\section{Giulio Clovio on Medals and on a Medallion}

The effigy of Giulio Giorgio Clovio (Grižane, Croatia, 1498 - Rome, January 5, 1578) the most famous miniaturist of the 16th c. - maximus in minimis - can also be seen on medals. Although we cannot complain that some of his great contemporaries did not portray him on canvas, it is unusual that during his lifetime only two medals were made or perhaps just one in two variants. The remainder were made after his death, some in our times.

The first, a double-sided medal, $40 \mathrm{~mm}$ in diameter, was first published in 1750 by Filippo Argelati, although he had not seen it. Later it was also described by other writers, for instance by A. Armand. A uniface medal of cast bronze, $32 \mathrm{~mm}$ in diameter exists at the Coins and Medals Department of the British Museum and has been published by various authors, starting with J. W. Bradley in 1891. In 1632 a representative marble epitaph consisting of an inscription topped by the miniaturist's portrait on an oval medallion was unveiled in the very well frequented Roman Basilica of S. Pietro in Vincoli.

In 1998, in the second volume of the monumental catalogue of Venetian medals by Piero Voltolina, one could see an apocryphal cast-bronze, uniface medal with a portrait for which the inscription claimed that it was that of G. G. Clovio, made in the second half of the 17th c., $48.5 \mathrm{~mm}$ in diameter. However, the profile of the man depicted does not resemble that of Clovio at all. The portrait of G. G: Clovio and some of his works found its place in the Croatian art of the medal of the 2oth c. Zdravko Brkić made a two-sided, cast bronze medal in 1978, $115 \mathrm{~mm}$ in diameter, with the portrait of the master on the obverse and a detail of a miniature by him from the Farnese Codex on the reverse. In the same year of the fourth centenary of Clovio's death, another double-sided, cast bronze medal, rather rough in style, was made by Ivan Belobrajdić. Damir Mataušić too, the most productive Croatian contemporary medallist, has also dedicated one of his medals and a plaquette to Covio's oeuvre: one of the medals on the ceremonial chain of the Dean of the Academy of Fine Arts in Zagreb (1979), as well as on a plaquette depicting Clovio's Adoration of the Shepherds (1999). The latter was made in several versions and size.

In 1998, when the 500th anniversary of Clovio's birth was celebrated, Aleksandar Kukec, the photographer, made a medal with Clovio's portrait on the obverse and an inscription on the reverse. To mark the same jubilee, the Croatian National Bank issued a 200 kuna silver coin, modelled by Kuzma Kovačić, with the miniaturist's portrait on the obverse and an initial from a codex of his on the reverse.

Translation: Ivan Mirnik

Dr. sc. IVAN MIRNIK (Zagreb, 1942.) diplomirao je arheologiju na Sveučilištu u Zagrebu. Od 1973. do umirovljenja 2011. radio je u Arheološkome muzeju u Zagrebu na Numizmatičkom odjelu. Magistrirao je 1974. s temom „Numizmatička tradicija u Hrvatskoj”, a doktorira s temom „Coin Hoards in Yugoslavia” na Arheološkom institutu Sveučilišta u Londonu. Autor je više od 450 bibliografskih jedinica (knjige, izvorni znanstveni i stručni radovi) te sedamdesetak novinskih članaka s brojnim temama (arheologija, numizmatika povijest, zaštita spomenika, genealogija, heraldika itd.).
IVAN MIRNIK, PhD (Zagreb, 1942) graduated in archaeology at the University of Zagreb. From 1973 to his retirement in 2011 he worked at the Zagreb Archaeological Museum Numismatic Department. He obtained the MA degree in 1974 with the thesis "Tradition of numismatic research in Croatia", at the University of London Institute of Archaeology obtained the degree of a Doctor of Philosophy with the doctoral thesis "Coin Hoards in Yugoslavia". He is the author of more than 450 books and original scientific/scholarly and professional papers with various topics (archaeology, numismatics, history, protection of monuments, genealogy, heraldry). 